\title{
Analisis Body Shaming terhadap Perempuan dalam Film Imperfect
}

\author{
Jocelyn Dominica ${ }^{1}$, Gregorius Genep Sukendro ${ }^{2 *}$ \\ ${ }^{1}$ Fakultas Ilmu Komunikasi, Universitas Tarumanagara, Jakarta \\ Email: Jocelyndominicaa@gmail.com \\ ${ }^{2}$ Fakultas Ilmu Komunikasi, Universitas Tarumanagara, Jakarta* \\ Email: geneps@fikom.untar.ac.id
}

Masuk tanggal : 15-12-2021, revisi tanggal : 06-01-2022, diterima untuk diterbitkan tanggal : 16-01-2022

\begin{abstract}
The author conducted this research with the aim of providing an overview of the representation of Body shaming contained in the film "Imperfect" directed by Ernest Prakasa. The approach used by researchers is interpretative qualitative. The author uses Roland Barthes' Semiotic Analysis with the meaning of denotation, connotation and myth as a research method. The data collection method is done by observation. The film "Imperfect" tells the story of a woman named Rara (played by Jessica Mila) who is born different from her younger sister, Rara has a thick body, brown skin and curly hair, very different from her younger sister who has a slim body, white skin and straight hair. Getting condescending gaze and also satirical treatment in the office environment has become daily food for Rara. Rara's concern for the body changed when she was demanded to change her appearance by the boss of the company where she worked so that she could be promoted. The results of this study indicate that the actions of body shaming are carried out either intentionally or unintentionally.
\end{abstract}

Keywords: body shaming, film, semiotics, woman

\begin{abstract}
Abstrak
Penulis melakukan penelitian ini dengan tujuan memberikan gambaran mengenai representasi body shaming yang terdapat dalam film 'Imperfect' disutradarai oleh Ernest Prakasa. Pendekatan yang digunakan peneliti adalah kualitatif interpretatif. Penulis menggunakan Analisis Semiotika Roland Barthes dengan pemaknaan denotasi, konotasi, dan mitos sebagai metode penelitian. Metode pengumpulan data dilakukan dengan observasi. Film 'Imperfect' menceritakan tentang seorang perempuan bernama Rarayang terlahir berbeda dengan adik perempuannya. Rara memiliki tubuh berisi, kulit sawo matang dan rambut keriting sangat berbeda dengan adiknya yang memiliki tubuh langsing, kulit putih dan rambut lurus. Mendapatkan tatapan yang merendahkan dan juga perlakuan yang menyindir di lingkungan kantor sudah menjadi makanan sehari-hari untuk Rara. Kepedulian Rara terhadap tubuh berubah ketika dirinya dituntut untuk mengubah penampilan oleh bos perusahaan tempat ia bekerja agar dapat naik jabatan. Hasil dari penelitian ini menunjukkan tentang perbuatan body shaming yang dilakukan baik sengaja maupun tidak sengaja.
\end{abstract}

Kata Kunci: body shaming, film, perempuan, semiotika

\section{Pendahuluan}

Media massa merupakan salah satu bagian dari komunikasi massa. Alat yang digunakan untuk menyampaikan pesan kepada penerima pesan atau khalayak umum dengan menggunakan alat kounikasi mekanis seperti radio, televise, surat kabar dan 
juga film(Canggara-2002). Kesimpulan dari pengertian diatas menyatakan bahwa media massa merupakan salah satu bagian dari komunikasi massa dan memiliki kemampuan untuk menyampaikan pesan, gagasan dan informasi kepada publik salah satunya adalah film.

Film merupakan suatu kombinasi antara upaya penyampaiaan pesan baik secara verbal dan non verbal seperti gambar yang bergerak. Film tidak pernah dianggap sebagai media pembujuk selalu dianggap media hiburan. Namun tanpa disadari kekuatan bujukan yang dimiliki film sangat besar. Film yang ditayangkan biasanya sesuai kebutuhan pasar penonton, tema-tema yang diambil biasanya diangkat berdasarkan dari permasalahan-permasalahan yang popular. Tayangan yang disajikan muncul dari ide-ide, kreatifitas, teknis, konsep dan tentunya dibutuhkan waktu yang banyak untuk menghasilkan karya yang berkualitas secara verbal ataupun non-verbal.

Pasal 1 Undang-Undang Nomor 33 Tahun 2009 bab1 memuat ketentuan tentang film yaitu film adalah karya seni dan budaya, merupakan pranata sosial dan media massa yang diproduksi berdasarkan kaidah kesenian dengan atau tanpa bunyi dan dapat ditampilkan. Menurut pengertian Effendi film adalah hasil kebudayaan dan sarana ekspresi seni. Sukendro (2013) mengemukakan bahwa berbicara tentang film adalah berbicara tentang media massa yang merupakan pernyataan budaya dalam berbagai kerangka kesenian. Informasi dalam film tersebut menggunakan mekanisme simbolik yang ada di otak manusia berupa isi pesan, bunyi, suara, dan dialog.

Penonton sebenarnya dapat memperoleh beberapa nilai dari film yang ditayangkan. Film juga dapat menjadi media kekerasan bagi perempuan. Kekerasan simbolik yang sering dialami oleh perempuan dizaman yang sudah berkembang ini biasanya di sebut dengan Body shaming. Salah satu film yang menarik untuk dikaji adalah Film Imperfect. Menurut definisi Oxford Living Dictionaries, body shaming memiliki arti sebuah tindakan mulai dari mengkritik, mengejek, sampai menghina dengan mengomentari sebuah fisik (bentuk maupun ukuran tubuh) dan penampilan seseorang. Body shaming adalah perasaan tidak nyaman yang dimiliki seseorang terhadap bentuk maupun ukuran tubuh yang dimiliki karena kritikan dan penilaian dari orang lain yang mengatakan bahwa bentuk dan ukutan tubuh tidka sesuai dengan standard ideal yang ada.

Film 'Imperfect' merupakan film terbaru dari seorang komika yang bernama Ernest Prakasa. Film ini adalah adaptasi dari novel ciptaan Meira Anastasia yang merupakan istri dari Ernest Preakasa berjudul: 'Imperfect': A Journey to SelfAcceptance. Buku tersebut berceritakan tentang penerimaan diri terhadap apa yang kita punya misalkan ukuran tubuh. Cerita filmnya akan berbeda, walaupun adaptasi dari buku. Buku berkisah tentang kehidupan istri Ernest Prakasa namun filmnya akan berbeda poin utamanya akan tetap sama yaitu mencintai diri sendiri dan penerimaan diri.

Hal ini menarik peneliti untuk mengetahui bagaimana tanda-tanda merepresentasikan body shaming dalam film 'Imperfect'. Rumusan masalah yang diambil dari latar belakang diatas yaitu bagaimana merepresentasikan body shaming dalam film 'Imperfect' dan dari rumusan masalah yang disampaikan tujuan penelitiannya adalah mendeskripsikan dan menganalisis perlakuan body shaming dalam Film 'Imperfect'. Peneliti berharap dapat memberikan manfaat secara akademis serta menambah ilmu pengetahuan baru mengenai kajian representasi body shaming dalam film yang dikaji dengan menggunakan teknik analisis semotika. serta manfaat praktis yang diharapkan dapat memberi referensi tambahan bagi peneliti 
yang ingin meneliti body shaming terhadap perempuan terutama dalam suatu media seperti film.

Menurut Roland Barthes, semiotika merupakan bagian dari linguistik, karena simbol pada bidang lain dapat dilihat sebagai bahasa, pengungkapan gagasan (makna, makna), unsur-unsur yang dibentuk oleh tanda dan ada dalam struktur. Dalam semiotika Barthes, penyuluhan adalah tingkat pertama dari sistem makna, dan konotasi adalah tingkat kedua. Dalam hal ini, simbol lebih berkaitan dengan makna tertutup.

\section{Metode Penelitian}

Penelitian ini merupakan penelitian dengan pendekatan penelitian kualitatif interpretatif yang menjelaskan fenomena atau objek penelitian sebanyak mungkin dengan mengumpulkan data. Sebuah studi yang tidak dapat ditemukan melalui prosedur statistik atau bentuk perhitungan lainnya. Penelitian kualitatif memberikan gambaran yang mendalam dan rinci tentang fenomena yang akan dipelajari.

Metode penelitian yang digunakan dalam penelitian ini adalah analisis semiotika Roland Barthes melalui tiga elemen yang dikemukakannya, yaitu makna denotasi , konotasi, dan mitos . Semiotika merupakan bagian dari ilmu linguistik, karena tanda dalam bidang lain dapat dikatakan sebagai bahasa yang mengungkapkan gagasan, unsur-unsur yang dibentuk oleh tanda, dan ada dalam struktur. Penelitian ini merupakan penelitian dengan metode analisis penelitian Roland Barthes didasari oleh bagaimana penelitian ini menganalisa subyek dan obyek yang ada dalam film Imperfect.

Subyek merupakan suatu bahasan yang sering muncul dalam penelitian. Manusia, benda, ataupun lembaga dengan keadaannya akan diteliti adalah sesuatu yang didalam dirinya melekat atau terkandung objek penelitian. Dalam penelitian ini subyek penelitianya adalah peneliti sendiri. Peneliti akan mencari dan memasukkan informasi-informasi penting untuk menganalisa unsur body shaming dalam film 'Imperfect' dengan dibantu junal-jurnal analisa serta teknik pengumpulan data semotika. Menurut Nyoman Kutha Ratna, benda adalah segala gejala yang ada dalam kehidupan manusia. Dari sumbernya, objek penelitian kualitatif menurut Spradley disebut situasi sosial, yang terdiri dari tiga unsur yaitu lokasi, pelaku, dan kegiatan kolaboratif. Obyek yang akan diteliti oleh peneliti adalah film Imperfect.

Pengumpulan data untuk penelitian ini yang pertama dengan teknik pengumpulan data observasi. Observasi adalah pengamatan yang dilakukan dengan merekam atau mengkodekan perilaku atau suasana individu, kondisi, dll. Observasi merupakan fakta yang didasarkan pada peristiwa empiris, yang melibatkan semua aktivitas sensorik, seperti pendengaran, penglihatan, pengecapan, peraba, dan pengecapan. Selain observasi peneliti juga melakukan pengumpulan data dengan cara dokumentasi. Teknik dokumentasi digunakan untuk mendapatkan data dalam bahan yang berbentuk catatan atau lisan sesuai keinginan peneliti.

\section{Hasil Temuan dan Diskusi}

Film berjudul Imperfect yang merupakan salah satu karya dari Ernest Prakasa dan film ini merupakan adaptasi dari novel berjudul sama karya Meira Anastasia, istri dari Ernest Prakasa. Film Imperfect menceritakan tentang seorang perempuan bernama Rara (diperankan oleh Jessica Mila) yang terlahir berbeda dengan adik 
perempuannya, Rara memiliki tubuh berisi, kulit sawo matang dan rambut keriting sangat berbeda dengan adiknya yang memiliki tubuh langsing, kulit putih dan rambut lurus. Mendapatkan tatapan yang merendahkan dan juga perlakuan yang menyindir di lingkungan kantor sudah menjadi makanan sehari-hari untuk Rara. Kepedulian Rara terhadap tubuh berubah ketika dirinya dituntut untuk mengubah penampilan oleh bos perusahaan tempat ia bekerja agar dapat naik jabatan. Kebiasaan sajian yang ditayangkan oleh film dimana seorang perempuan harus kurus, putih, tirus baru dapat dikatakan sebagai seseorang yang cantik, sehingga terciptanya standard kecantikan dalam kehidupan sosial. Sudah menjadi hal yang biasa ketika seseorang berbicara dan membahas fisik lawan bicara tanpa tau akibat dari perkataan tersebut.

Setelah melakukan penelitian menggunakan analisis semiotika Roland Barthes, peneliti memilih beberapa scene yang merepresentasikan Body shaming yang digambarkan pada film tersebut. Perlakuan Body shaming digambarkan melaluin penampilan dan fisik dari pemeran serta tingkah laku dan juga perkataan. Ibu Rara yang mengatakan dirinya pusing melihat Rara seperti paus terdampar. Cara mengomentari, mengkritik tubuh seseoraang atau diri sendiri secara negatif, bisa diklasifikasikan salah satu betuk Body shaming. Siapapun bisa jadi korban, tak memandang usia dan jenis kelamin, bisa dilakukan siapa saja, secara sadar ataupun tak sadar. Sebutan seperti Keling bagi berkulit hitam, paus bagi yang bertubuh besar, tiang listrik yang kurus tinggi, dan sejenisnya sering kita dengar. Bahkan perumpamaan itu dianggap biasa dalam perkawanaan dan keluarga, padahal tak semua orang rela disebut seperti itu. Setiap orang memiliki ketahanan mental yang berbeda dalam menyikapi hal-hal yang berurusan dengan tubuhnya, dan tidak semua orang nyaman membicarakan tubuhnya.

Saat teman-teman ibunya Rara berkata kepada Rara dan Lulu bahwa mereka sangat berbeda sekali padahal mereka juga sudah mengetahu bahwa Rara lebih mirip ayahnya dan Lulu mirip ibunya sehingga mereka memiliki tampilan fisik yang berbeda. Sudah menjadi hal yang umum perempuan yang memiliki tubuh yang lebih berisi selalu disindir untuk mengingat lemak yang ada dalam tubuh dan juga disamakan dengan ibu yang sedang hamil. Pada umumnya ibu yang sedang hamil akan menjadi berisi karena nutrisi yang dibutuhkan semakin banyak karena dalam perut ada calon bayi serta pola makan yang tidak beraturan sehingga badan ibu hamil akan lebih berisi dari sebelumnya ditambah dengan perut yang akan semakin besar karena seiring berjalannya waktu janin dalam perut akan berkembang.

Ada adegan Maria yang ingin meluruskan rambutnya yang keriting dibantu oleh Prista yang menutupi tompel di dahi dengan menggunakan poninya sehingga menandakan bahwa mereka merasa tidka percaya diri sehingga menutupi hal yang mereka miliki, adegan dimana Rara juga berusaha keras merubah penampilan dengan belajar dandan dan juga berolahraga sampai ia mencapai standard kecantikan yang ada dalam kehidupan sosial lalu ia berhasil mencapai kesuksesan dalam pekerjaan yang menandakan bahwa seorang perempuan yang sesuai standard kecantikan barulah bisa sukses.

Salah satu kasus yang terjadi dikehidupan nyata adalah dirilis pada Minggu,22 November 2020 pukul 12:30 WIB yang berisi 'HRD Restoran Sushi Dituding Pecat Karyawan karena Gemuk, Ini kata Manajemen'. Sebuah restoran sushi di kawasan BSD banjir hujatan netizen setelah oknum karyawannya diduga melakukan body shaming. Pihak manajemen angkat bicara. Kisah oknum HRD yang melakukan body shaming ini heboh di Twitter setelah seorang calon karyawan 
membeberkan pengalamannya. Bukan karena Ezzy melakukan kesalahan fatal, dalam percakapan lewat pesan singkat ini bisa dilihat kalau pekerja di restoran ini tidak diperkenankan memiliki badan gemuk. Unggahan ini langsung menyita perhatian netizen. "Sebelumnya saya minta maaf, sepertinya gak bisa dilanjut. Saya juga mohon maaf, itu menyakitkan hati loh pak/bu. Lalu kenapa di awal interview saya bisa diterima ya? Padahal ketemu ga ada bilang badan gendut gak boleh kerja di situ?" beber Ezzy. Masih dengan percakapan yang sama, Ezzy juga mengatakan kalau kalimat yang diucapkan ini menyakiti hatinya dan termasuk body shaming.

Kasus di atas merupakan salah satu contoh dari body shaming yang dilakukan kepada orang lain. Banyak sekali hal-hal yang dapat terjadi tanpa sepengetahuan seseorang. Body shaming yang dilakukan adalah ketika terdapat orang mengatakan bahwa tubuhnya gendut, hitam dan lain sebagainya yang berhubungan dengan fisik sehingga korban akan merasa rendah diri, marah kepada diri sendiri, stress dan tidak percaya diri.

\section{Simpulan}

Berdasarkan analisis yang dilakukan dapat disimpulkan bahwa di dalam film Imperfect karya Ernest Prakasa, body shaming banyak dilakukan karena adanya tuntutan agar perempuan terlahir dan berpenampilan sesuai dengan standard kecantikan yang ada dalam kehidupan sosial. Dalam konteks Ilmu Komunikasi dan periklanan, penulis dapat menyimpulkan bahwa hasil penelitian ini dapat diterapkan dalam dunia periklanan, terutama tayangan televisi. Misalnya dalam tayangan televisi yang isinya mengenai iklan shampoo di mana perempuan yang memerankan akan memiliki rambut yang panjang dan lurus sehingga itu merupakan body shaming terhadap perempuan yang memiliki rambut keriting.

\section{Ucapan Terima Kasih}

Peneliti ingin menyampaikan terima kasih kepada Ali Karimun dan Rosni yaitu orang tua dari peneliti, Vanessa Salim, Ricky Suryanto, Theo Wijaya, Scelly Alvionita yang telah mendukung peneliti dalam melakukan penelitian ini.

\section{Daftar Pustaka}

Bungin, B. (2011). Penelitian Kualitatif. Jakarta: Kencana Predana Media.

Busanapedia. (20 September 2020). Perbedaan Standard Kecantikan Wanita Setiap Zaman. Diakses dari http://busanapedia.blogspot.com/2015/05/perbedaanstandar-kecantikan-wanita.html

Cangara, H. (2010). Pengantar Ilmu Komunikasi. Jakarta: Rajawali Pers.

Eartha Beatricia Gunawan, Ahmad Junaidi (2020). Representasi Pendidikan Seks dalam Film Dua Garis Biru (Analisis Semiotika Roland Barthes). Jakarta. Universitas Tarumanagara

Hasfi, Wirda Tri (2017). Representasi Simbol Keislaman Dalam Film (Analisis Semiotika Roland Barthes "My name is Khan")

Hazismalyadi, Hazismalyadi (2019). Representasi Body Shaming pada drama Televisi My Id Is Gangnam Beauty (Analisis Semiotika Roland Barthes). Jakarta. Universitas Bakrie 
Liputan6. (20 September 2020). Seperti Apa Standard Kecantikan dari Zaman ke Zaman.

Diakses

dari

https://www.liputan6.com/lifestyle/read/2169617/seperti-apa-standar-

kecantikan-wanita-dari-zaman-ke-zaman

Mc.Quail, Dennis. (2005). Teori Komunikasi Massa. Jakarta: Erlangga

Moleong, Lexy J. (2005). Metodologi Kualitatif Edisi Revisi. Bandung: PT. Remaja Rosda Karya

Nisa, Ishmatun (2014). Analisis Semiotika Pesan Moral Dalam Film Jokowi. Jakarta. Universitas Islam Negeri Syarif Hidayatullah

Sobur. (2004). Analisis Teks Media:Suatu Pengantar Untuk Analisis Wacana, Analisis Semiotika dan AnalisisFraming. Bandung: Remaja Rosdakarya.

Sugiyono. (2009). Metode Penelitian Kuantitatif, Kualitatif dan R\&D. Bandung: Alfabeta

Sukendro, Gregorius Genep (2013) Film Indonesia: Gelombang Pop Culture Yang Melupakan Tuan Rumah. Jakarta. Universitas Tarumanagara

Syadian, Triadi (2015). Analisis Semiotika Pada Film Laskar Pelangi. Jakarta. Universitas Potensi Utama

Taqiyya, Hani (2012). Analisis Semiotika Terhadap Film In The name of God. Jakarta. Universitas Islam Negeri Syarif Hidayatullah

Vera, Nawiroh. (2014). Semiotika Dalam Riset Komunikasi. Bogor: Ghalia Indonesia

Weisaikurnai, Bagus Fahmi (2017). Reprsentasi Pesan Moral Dalam Film Rudy Habibie Karya Hanung Bramantyo (Analisis Semiotika Roland Barthes). Pekanbaru. Universias Riau 